University of Nebraska - Lincoln

DigitalCommons@University of Nebraska - Lincoln

\title{
Women at war: Understanding how women veterans cope with combat and military sexual trauma
}

Kristin M. Mattocks

Health Services Research and Development Services

Sally G. Haskell

Yale University

Erin E. Krebs

Indiana University School of Medicine

Amy C. Justice

Yale University

Elizabeth M. Yano

University of California - Los Angeles

See next page for additional authors

Follow this and additional works at: https://digitalcommons.unl.edu/publichealthresources

Part of the Public Health Commons

Mattocks, Kristin M.; Haskell, Sally G.; Krebs, Erin E.; Justice, Amy C.; Yano, Elizabeth M.; and Brandt, Cynthia, "Women at war: Understanding how women veterans cope with combat and military sexual trauma" (2012). Public Health Resources. 184.

https://digitalcommons.unl.edu/publichealthresources/184

This Article is brought to you for free and open access by the Public Health Resources at DigitalCommons@University of Nebraska - Lincoln. It has been accepted for inclusion in Public Health Resources by an authorized administrator of DigitalCommons@University of Nebraska - Lincoln. 


\section{Authors}

Kristin M. Mattocks, Sally G. Haskell, Erin E. Krebs, Amy C. Justice, Elizabeth M. Yano, and Cynthia Brandt 


\title{
Women at war: Understanding how women veterans cope with combat and military sexual trauma
}

\author{
Kristin M. Mattocks ${ }^{\mathrm{a}, \mathrm{e}, *}$, Sally G. Haskell ${ }^{\mathrm{a}, \mathrm{b}}$, Erin E. Krebs ${ }^{\mathrm{a}, \mathrm{c}}$, Amy C. Justice ${ }^{\mathrm{a}, \mathrm{b}}$, Elizabeth M. Yano ${ }^{\mathrm{a}, \mathrm{d}}$, \\ Cynthia Brandt ${ }^{\mathrm{a}, \mathrm{b}}$ \\ a Department of Veterans Affairs, Health Services Research and Development Services 810 Vermont Avenue Northwest, Washington DC 20420-0002, USA \\ ${ }^{\mathrm{b}}$ Yale University, 333 Cedar Street, New Haven, CT 06510, USA \\ ${ }^{\mathrm{C}}$ Indiana University School of Medicine HSRD (11H), Roudebush VAMC 1481 W. 10th Street, Indianapolis, IN 46202, USA \\ ${ }^{\mathrm{d}}$ University of California, Los Angeles, Center for Health Sciences, 650 Charles E. Young Drive South 16-035, Los Angeles, CA 90095-1772, USA \\ e University of Massachusetts Medical School, 55 Lake Avenue North, Worcester, Massachusetts 01655, USA
}

\section{A R T I C L E I N F O}

\section{Article history:}

Available online 11 December 2011

\section{Keywords:}

Coping

Adaptation

Mental health

Sexual harassment

Stress

Trauma

Women

Iraq

Afghanistan

USA

Veterans

War

\begin{abstract}
A B S T R A C T
The wars in Iraq (Operation Iraqi Freedom, OIF) and Afghanistan (Operation Enduring Freedom, OEF) have engendered a growing population of US female veterans, with women now comprising $15 \%$ of active US duty military personnel. Women serving in the military come under direct fire and experience combatrelated injuries and trauma, and are also often subject to in-service sexual assaults and sexual harassment. However, little is known regarding how women veterans cope with these combat and military sexual trauma experiences once they return from deployment. To better understand their experiences, we conducted semi-structured interviews with nineteen OEF/OIF women veterans between January-November 2009. Women veterans identified stressful military experiences and post-deployment reintegration problems as major stressors. Stressful military experiences included combat experiences, military sexual trauma, and separation from family. Women had varying abilities to address and manage stressors, and employed various cognitive and behavioral coping resources and processes to manage their stress.
\end{abstract}

Published by Elsevier Ltd.

\section{Introduction}

Since the inception of the wars in Iraq (Operation Iraqi Freedom, OIF) and Afghanistan (Operation Enduring Freedom, OEF), more than 150,000 United States female service members have been deployed overseas (Department of Defense, 2010). Over one hundred and sixty women have been killed during their OEF/OIF deployments (Department of Defense, 2010), thousands of women have been seriously injured, and an unknown number suffer significant mental health problems as a result of their exposure to combat-related violence, military sexual trauma, and other stressors during their military deployments (Mulhall, 2009). Recent studies suggest that more than $15 \%$ of service members returning from Iraq and $11 \%$ of service members returning from Afghanistan have met the screening criteria for major depression, generalized

\footnotetext{
* Corresponding author. University of Massachusetts Medical School, Department of Quantitative Health Sciences, 421 North Main Street, Leeds, MA 01053-9764, USA. Tel.: +1 4135844040 .

E-mail address: Kristin.Mattocks@va.gov (K.M. Mattocks).
}

anxiety, or posttraumatic stress disorder (Hoge et al., 2004; Hoge, Terhakopian, Castro, Messer, \& Engel, 2007).

Women's wartime experiences and the challenges they face when trying to reintegrate into their work, family, and social lives post-deployment have been overshadowed by the experiences of male OEF/OIF veterans facing similar challenges. A substantial body of research has examined the consequences of combat zone deployment, including the prevalence of posttraumatic stress disorder (PTSD), traumatic brain injury (TBI), depression, substance abuse and other physical and mental health problems among returning war veterans, but the majority of this research has focused on male veterans (Baker et al., 2009; Cohen et al., 2010; Erbes, Westermeyer, Engdahl, \& Johnsen, 2007; Jakupcak et al., 2009; McDevitt-Murphy et al., 2010; Schnurr, Lunney, Bovin, \& Marx, 2009; Seal et al., 2010, 2009). The justification for the focus on male veterans is twofold. First, male troops substantially outnumber female troops and, therefore, greater numbers of male veterans return to the United States with serious mental and physical health problems. Second, the types of military occupational roles that male servicemembers have occupied have, at least 
until recently, given them more direct exposure to combat-related trauma and stress than women. Though a growing number of studies have begun to focus on women's medical and mental health conditions after return from deployment, few studies have examined women's experiences in war, and how they cope with these experiences once they return to the United States and try to reintegrate with their families, jobs, and communities.

Previous research has examined both deployment and postdeployment stressors experienced by military personnel (King, King, Vogt, Knight, \& Samper, 2006; Street, Vogt, \& Dutra, 2009; Vogt, Pless, King, \& King, 2005; Vogt, Samper, King, King, \& Martin, 2008). Deployment-related stressors can include missionrelated stressors, such as combat experiences and difficult living and working environments, as well as interpersonal stressors, including concerns about family disruptions and sexual harassment. Post-deployment stressors include exposure to stressful life events after deployment, which may include stressors related or unrelated to deployment, and may also include efforts at reintegration. In the past two decades, legislative and Department of Defense (DOD) policy changes have greatly expanded the occupational roles available to women serving in the military (Donegan, 1996; Mulhall, 2009). These expanded occupational roles have broadened women's exposure to combat-related violence and the stress of military service. Though women are still prohibited from serving in direct combat roles (e.g. infantry) they may serve in a variety of positions that put them at risk for injury or death. The wars in Iraq and Afghanistan have further blurred the line between combat and non-combat roles, as these wars have been characterized by guerilla fighting in urban war zones (Street et al., 2009). For example, serving as a member of the military police (MP) is considered a non-combat occupation, but women serving as MPs provide convoy and unit security, control traffic, and enforce military regulations. These roles may require female soldiers to search for improvised explosive devices (IEDs), which have caused up to $75 \%$ of fatalities in Afghanistan in 2009 (Joint Improvised Explosive Device Defeat Organization). Consequently, though women do not serve in direct combat positions, a recent study suggests that approximately three quarters of women deployed to Iraq have been exposed to one or more combat experiences (Dutra et al., 2011), which is on par with studies comprised of primarily OEF/OIF male servicemembers (Milliken, Auchterlonie, \& Hoge, 2007).

Actual or perceived danger is only one source of stress faced by female servicemembers (Kang, 2006). Women serving in the military must also cope with the threat of gender-based violence during deployment (Kimerling, Gima, Smith, Street, \& Frayne, 2007; Kimerling et al., 2010; Yaeger, Himmelfarb, Cammack, \& Mintz, 2006). "Gender-based violence" is a term introduced in 1993 as the United Nationals adopted the Declaration of Violence Against Women, which describes violence against women as "Any act of gender-based violence that results in, or is likely to result in, physical, sexual, or psychological harm or suffering to women including threats of such acts, coercion or arbitrary deprivations of liberty, whether occurring in public or private life" (p.1). Genderbased violence, specifically violence against women, is highly prominent, particularly in the context of war, and may be inflicted upon both civilian and military women alike (Linos, 2009), though whether there is a differential effect on civilian and military women is unknown. Military sexual trauma (MST) is the term used by the Department of Veterans Affairs to refer to sexual assault or repeated, threatening sexual harassment that occurred while the veteran was in the military. Recent evidence from OEF/OIF veterans suggests that $15.1 \%$ of women and $0.7 \%$ of men reported military sexual trauma when screened (Kimerling et al., 2010).

The effect of deployment on men and women may also differ as a result of women's responsibilities at home. Though the gap in household responsibilities has narrowed over the years (Bianchi, Milkie, Sayer, et al, 2000), women still have more responsibilities for child care, cooking meals, housekeeping, and other tasks. Consequently, when women deploy, responsibilities for these activities must be given to spouses, family members, or friends, contributing to women's deployment-related stress (Vogt et al., 2005). Recent studies suggest that over 40 percent of active duty women have children (Department of Defense, 2006), yet rising divorce rates for female servicemembers (Adler-Baeder, Pittman, \& Taylor, 2006) place added stress on women who must find alternate arrangements for childcare during deployment. More than 30,000 single mothers have deployed to Iraq and Afghanistan (Department of Defense, 2010), but while children of partnered women usually stay with their other parent during their mother's deployment, children of single mothers typically move in with other relatives (e.g. grandparents, aunts) (Kelley et al., 2002). Furthermore, deployment stress may be more profound among women in the Guard and Reserve. As Guard and Reserve members are primarily used in the civilian sector, deployment of women in the Guard and the Reserve involves transitions to and from their usual jobs, prolonged departure from their families, and less social support from their home communities as compared to active duty personnel living on a military base (Foster, 2011).

These and other stressors experienced by women during their military deployments are well-documented (King et al., 2006; Street et al., 2009; Vogt et al., 2008). How women in the military cope with both deployment and post-deployment stressors is the subject of recent scientific inquiry. Much of the literature has focused exclusively on the relationship between inadequate coping processes and psychological outcomes, such as post traumatic stress disorder (Engel, Liu, McCarthy, Miller, \& Ursano, 2004; Farley \& Catano, 2006; Hoge et al., 2007; Lambert, 2004; Rodrigues \& Renshaw, 2010; Sharkansky et al., 2000; Suvak, Vogt, Savarese, King, \& King, 2002), while other literature focuses on physiological responses to stress (Bruner \& Woll, 2011). Other literature has focused on risk factors for inadequate coping responses among women in the military, including pre-deployment factors (childhood environment, prior stressors) and post-deployment factors (other life stressors and social support) (Carter-Visscher et al., 2010; King, King, Fairbank, Keane, \& Adams, 1998; Vogt \& Tanner, 2007). Ferrier-Auerbach, Erbes, Polusny, Rath, and Sponheim (2010) found that women deployed to a combat zone were more likely to experience emotional distress in response to combat trauma than men, and that frequent contact with friends and family at home and leadership support during deployment may improve the ability to cope with deployment-related stressors.

Moos and Schaefer's model of coping resources and processes (1993) suggests that coping resources, including personal and social factors that influence how individuals manage life crises and transitions, as well as coping processes, which are the cognitive and behavioral efforts that individuals use in stressful situations, are important to consider when evaluating how individuals cope with stress. Cognitive approach coping strategies are those in which an individual appraises the situation, and evaluates how to handle the situation using the coping resources available at that time (Lazarus \& Folkman, 1984). Behavioral approach coping strategies are those strategies used to seek guidance, support, and positive concrete actions to deal directly with the stressor. In contrast, cognitive avoidance strategies are those aimed at denying or minimizing the seriousness of a crisis or its consequences, as well as accepting a situation as it is and deciding it cannot be changed. Conversely, behavioral avoidance coping strategies involve trying to replace the losses involved in a certain situation with alternative rewards, such as binge eating or substance abuse. Studies have examined deployment-related stressors and coping strategies separately 
(King et al., 2006; Rodrigues \& Renshaw, 2010; Vogt et al., 2005), but as the two areas are closely interwoven, both need to be considered together to fully understand the full impact of women's wartime experiences and the impact these experiences on women's readjustment after military service.

Given these gaps in the literature, what is needed is a thorough examination of women's experiences with combat zone deployment, and an assessment of gender-specific deployment-related stressors and coping strategies. Thus, this study was conducted to examine U.S. women's military deployment experiences, including combat-related exposure, military sexual trauma, separation from family, and gender discrimination in the military, and to explore the nature of women's coping strategies after return from military deployment.

\section{Methods}

\section{Setting and sample}

This study is a qualitative study nestled in a larger research study, the Women Veterans Cohort Study (WVCS). WVCS is a twophase longitudinal study examining healthcare utilization, health outcomes, and costs of care among a cohort of OEF/OIF male and female veterans in VA care. The sampling frame for the overall study is the OEF/OIF roster, provided to the VA by the Department of Defense Manpower Data Center's (DMDC) Contingency Tracking System. The OEF/OIF roster is a database of veterans who have separated from OEF/OIF military service and enrolled in VA healthcare between 10/1/2001-04/30/2008 ( $N=406,802)$. Roster information includes veterans' sex, race, date of birth, deployment dates, armed forces branch (Army, Navy, Air Force, Marines, or Coast Guard) and component (National Guard, Reserve or active duty). Our final sample included 43,078 women who served in OEF/ OIF and received VHA health care after return from deployment.

Phase I of the WVCS study is a database analysis of gender differences in healthcare utilization, healthcare costs, and health outcomes of the 406,802 male and female veterans in the OEF/OIF database. Data on veterans identified through the OEF/OIF roster were linked to administrative and clinical data contained within the VHA National Patient Care Database (NPCD) and Decision Support Systems (DSS). These databases provide healthcare utilization information and cost data, pharmacy and laboratory data, and health encounters and coded diagnostic and procedure data associated with inpatient and outpatient encounters.

Phase II of the study is a prospective survey of male and female $\mathrm{OEF} / \mathrm{OIF}$ veterans at two large VA facilities, one in the northeast and one in the midwest. Letters were sent to all male and female veterans on the OEF/OIF roster who lived within 100 miles of each facility $(n=2000)$. Patients expressing interest in the study either met with or called the research coordinator. Prospective subjects were read a description of the study, had questions answered about enrollment and possible adverse consequences of participation, and were screened for eligibility. Eligibility criteria included the ability to speak and read English, and participation in Operation Enduring Freedom or Operation Iraqi Freedom. Those who agreed to participate were given an appointment at which they signed the informed consent and were asked to complete the baseline survey. Participants were also asked to complete follow-up surveys one and two years, respectively, after the baseline survey. The current study, as well as the larger WVCS study, was approved by the VA Connecticut Healthcare System and by Yale University.

Six hundred and fifty veterans on the OEF/OIF roster were women registered to receive care at the northeast VA facility. Of these women, 74 agreed to participate in Phase II (prospective survey) component of the study. These 74 women were asked by a research associate if they would be interested in participating in a semi-structured interview with a trained qualitative interviewer. Women who agreed to participate in the semi-structured interview ( $n=19)$ signed a separate consent form for the semi-structured interview. Each woman was paid $\$ 25.00$ for participating in the interview. Interviews lasted, on average, $45 \mathrm{~min}$, and were conducted between January-November 2009. For the purposes of analysis and reporting, each woman was assigned a pseudonym by the author.

At the conclusion of the study, we ascertained mental health conditions for each woman by reviewing mental health diagnoses in the VA's administrative and clinical data contained within the VHA National Patient Care Database (NPCD). We focused on mental health conditions (depression, PTSD, and anxiety disorder) that are highly prevalent, and often disabling, conditions among veterans in the VA. Women veterans were considered to have a mental health diagnoses if they had 2 or more outpatient or 1 or more inpatient ICD-9-CM code for major and mild depression, PTSD, or anxiety disorder at any time since their enrollment into the VA Healthcare System. To reduce potential information bias caused by a distorted evaluation of information regarding the relationship between stress and coping mechanisms and mental health diagnoses of the participants, the investigators did not link specific comments from the participants to clinical mental health diagnoses assigned by VA clinicians.

\section{Data collection and analysis}

A semi-structured interview format allowed respondents to talk freely about their military experiences, including their jobs in the military, living conditions during deployment, deployment-related stressors, challenges of returning to the United States after deployment, and stress-related coping mechanisms. The interview guide was revised during the course of data collection and analysis so that categories and dimensions (properties) of categories could be found and more fully explored. Interviews were audio-recorded, transcribed, and entered into Atlas.ti (Scientific Software Development, 1997).

Each transcript was read in its entirety by two members of the study team to gain a sense of each veteran's experience. We used open coding, where each coder independently reviewed the transcripts line-by-line, creating code definitions as concepts emerged inductively from the data. Coders met to compare codes, resolve discrepancies, and review the code structure. The constant comparative method of qualitative analysis was used to compare coded segments of text to expand existing themes and identify new themes. Codes were refined until we reached a final coding structure, including a total of 20 codes capturing the major concepts in the data, which was then applied to all of the transcripts. The themes presented in the current analysis emerged from specific codes focused on participant experiences of deployment stressors, participant post-deployment experiences, participant familial and social context, and participant coping strategies.

\section{Results}

Nineteen women who served in OEF/OIF participated in the interviews. The mean age of the sample was 37; the women ranged from 23 to 55 years of age. Fifty percent of the women were members of the National Guard and $40 \%$ were members of the Army or Navy Reserves. Of the 19 women interviewed, seventy-nine percent were white; all had at least a high school degree, $26 \%$ had a Bachelor's degree, and $32 \%$ had a graduate or professional degree. Thirty-two percent of the women in the study had a clinical diagnosis of PTSD, while $11 \%$ had a diagnosis of major depression, and another $11 \%$ had received a diagnosis of anxiety disorder. 
Women veterans who had recently returned from war identified stressors that fell into two major categories, as described by others (King et al., 2006; Vogt et al., 2008)—stressful military experiences and post-deployment reintegration problems. We identified subgroups of stressors in each of these categories. Women's ability to address and manage stressors varied considerably and they employed various cognitive and behavioral coping resources and processes to manage their stress. Below is a detailed description of each of the major subgroups of stressors followed by a description of the behavioral and cognitive coping strategies women used to alleviate the stress.

\section{Stressful military experiences}

\section{Combat-related experiences}

Women in this study reported observing horrific combatrelated violence, and many acknowledged that these experiences had left them struggling with significant mental health problems, including PTSD and depression. For most women, these experiences were linked to their occupational roles during deployment. Women who were medics, nurses, members of the military police, or convoy drivers reported stressors such as carnage in emergency rooms, perceived danger while patrolling unsecured areas, and the threat of IED explosives along the routes they drove.

One woman in the group, Maria, served as a member of the military police patrolling the streets of Baghdad. Maria had been diagnosed with PTSD following her return from deployment, and had been hospitalized several times because of her suicidal ideation in response to the painful experiences she had endured in Iraq. Though several years had passed since her deployment, she could not keep back the tears when she shared her experiences:

I had the unfortunate experience of having to kill a child, an Iraqi child. Our convoy had broken down and this kid came running for us, he wouldn't stop and it was me and my battle buddies or the kid and they were using kids as bait. The kid was trying to sell us Coca-Cola soda, but really the kid was wired. So it had to be the kid that was going...

Combat-related stress occurred not only among women who patrolled the streets of Baghdad, but also among women working in emergency rooms or on medical transport missions. Jean described the day-to-day challenges she faced as an emergency room nurse in Iraq, with the duel stresses of caring for those who had been injured and fearing for her own safety:

We got patients literally from wherever the battlefield of the day was. We took care of soldiers and civilians including children and probably saw the worst that could be done to a human being by another human being. It's not like we saw traumas every single day but the ones that we had were pretty brutal. We saw people with their limbs blown off, severe head injuries, children, you know, with bad injuries, and even military working dogs that got hurt in the course of the battle. We were probably mortared almost every single day and sometimes the VBIEDs (Vehicle Borne Improvised Explosive Devices) were so powerful when they exploded outside the gate that, you know, it knocked us down it was so loud and forceful.

\section{Military sexual trauma}

One of the most difficult types of stress faced by women during their military deployments was the threat of sexual trauma. Consistent with other studies (Kimerling et al., 2007, 2010; Yaeger et al., 2006), women experienced different forms of sexual trauma, including sexual harassment, sexual coercion, and even rape. Often, women spoke of how sexual harassment or sexual coercion was tied to opportunities for promotion. Women who were promoted were assumed to have performed sexual favors for those in charge. Grace recounted her experience:

We would drive past \{male soldiers on the base and they made hand signals for different sexual things that they wanted to do to somebody. I mean these guys were married and most of them their wives were pregnant, you know, at home with their kids or just had kids and they were deployed. But, you know, they did it even more when I would say, you know, you need to stop. And then I brought it up to my superiors. I was like this needs to stop. This is just getting ridiculous and then it went on even worse and they did nothing. They did absolutely nothing.

Every time I got promoted, every single time, they would start by saying 'Oh it's only because you slept with so and so or you gave so and so a blow job or you did that or you did this and it's obviously completely not true.

Similarly, Glenda tells of her experiences with sexual harassment and rape in the military.

One of the problems over in Iraq for female soldiers is that there is a lot of sexual harassment and rape is huge. And it does not matter if you're 18 or 58 . It does not matter. Women serving over there don't have to be worried about enemy fire. They have to be worried about the guy that's next to them, you know, that's supposed to be protecting and taking care of them and a lot of times he becomes like public enemy number one for them.

\section{Separation from family}

Women spoke about the challenges of serving in the military while also being a mother to young children. Several women left for Iraq or Afghanistan for more than a year and made difficult decisions about with whom to leave their children during deployment. Some women felt comfortable leaving their children with their husbands; other women in the group, particularly single mothers, made the decision to leave their children with grandparents. Jill came from a large military family and grew up with a father who spent much time away for military duties. As a child, Jill was used to her mother caring for her four siblings and herself as a single parent, so Jill did not find it as difficult as she had imagined to leave her daughter behind with her mother:

When I left for Iraq, my daughter was four months old. But it really wasn't too bad because it was the perfect age for her. You know, she didn't really know too much of what was going on, like she would now. And it wasn't too bad for me because I don't think I got too big on the mother thing yet because she was only four months old. So it wasn't really too hard to even let go because I hadn't been a mother that long.

Similarly, Carol recounted how she handled the stress of being away from her children during the year and a half she was deployed:

When I went to Iraq, it was tough to leave my three kids but I felt I had a job to do and I couldn't worry too much about home. You shut off your mind to it, I think, because it's a whole separate world and you just say, ok, this is what I am, this is what I'm doing. When I talked to my kids on the phone it was just surface level stuff, not trying to get too deeply into what was going on with them because then the emotional side of me would come and its just so hard to try and deal with the harsh environment that you're in and still deal with the emotions of kids and the fact that you're missing them. When you talk to them, you just keep it simple, just simple things. And then you just go back to 
what you're doing, go back to your work. But it was the clear, clear separation that I really had to make that decision that I was going to separate myself from home and what was going on there. I knew my husband could handle it. He would be fine and get through it.

\section{Post-deployment reintegration problems}

The other major category of stressors identified by women included challenges of reintegrating into society upon return from war. Simple everyday tasks like driving down the highway become problematic for women suffering from the lingering effects of war. Some women were formally diagnosed with PTSD upon return to the United States and others just guessed that PTSD was the reason their daily lives were difficult to negotiate.

\section{Leaving the war behind}

Many women talked about the seeming threats associated with mundane tasks after having served in a war-torn area. Nancy, who was receiving treatment for PTSD at the time of the interview, recounted her struggle with leaving the war behind:

When I first returned, I was paranoid of everything and everybody within my perimeter, 360. I'm driving in the middle lane of the highway and I'm watching everything and it's raining and I'm like 'Oh, no! There's somebody coming up on my left!' and I'm holding onto that steering column and it's like life, limb, and eyesight.

\section{Janet had similar experiences}

You know carcasses, the dead deer on the side of the road, still irks me, still freaks me out and I'm looking real quick and I'm like 'I'm coming into your lane, buddy because I'm not even trying to drive by this thing cause God knows if it's going to blow up!'.

Arlene had been constantly exposed to mortar attacks during her deployment in Iraq and continued to find daily routines challenging:

When I first came home they were dynamiting near a grocery store where I shop. The first time I heard it I went right down to the ground in the store. But, I didn't lie flat, though. I caught myself and then I pretended I was looking for something on the bottom shelf. I was like, "Well, I'll just pretend I'm really looking at something on the bottom shelf here".

Nightmares are almost a given. Every night at least, at least once I have a bad dream. It's to the point where I wake up soaked in sweat. I mean just completely drenched. I don't even know how I can sweat that much and the bed sheets are completely soaked and my husband will wake up and be like what the hell? What's going on? You know, because I'll be screaming or I'll be shaking or I'll fight in my sleep and the dreams are always about the same thing. They're always about me being raped and killed every single time. The people change but it's always the same plot and it's always the same concept. And in the end I always die.

\section{Disrupted relationship with family and friends}

The majority of women in the study made conscious decisions not to discuss their military experiences with friends or family. Most women felt their friends and family members would not understand what they had experienced, so rather than reach out to share their difficult memories, they kept them to themselves. Sharon worked as a nurse practitioner at an army base in Iraq and explained how difficult it was for her to share the memories of the horrific damage she had witnessed to human bodies while working in the trauma unit:

I very rarely, very rarely, talk about my experience in Iraq. You know you should talk about it, but treating people that have been blown up and all that is not that relatable of an experience to most people you meet.

Other women spoke of returning home to find household matters in disarray. Several women found that their husbands or fiancés had mismanaged their bank accounts, and that a significant amount of money had been squandered while they were serving in Iraq or Afghanistan.

I came back (from Iraq) a little angry because here I was over there and I came to find out my husband had been flying all over the country and going out drinking every night with the guys on the money I was making while I was over there. He was supposed to have been paying off bills and when I come home it was like 'You were having a grand old party and you didn't pay off anything!' I asked him, 'Where's all the money? I mean, where'd all the money go?'

When Rita deployed to Iraq, she left her three children with her husband who cared for them well. But when she returned from deployment, she found it difficult to find her place in the family again, and learned that her husband had done some things slightly differently than she had done them. Perhaps most importantly, she found that her children had changed in many ways, and getting to know her children again was a challenge. Rita recounts,

When I returned I didn't know my kids anymore. Before I left, I knew their dress sizes, their shoe sizes, everything about them. But I was gone for a year and a half and so much changed in that time. I still remember the first day I took my son to school after I returned. I took him to school and made his lunch and picked him up at the end of the day. I said, "Oh, you didn't eat your Fig Newtons", and he said, "Ma! I don't eat Fig Newtons anymore!"

Often forgotten among veterans are the young men and women who must return to college campuses to resume classes after their deployments. With the exception of a recent RAND report detailing reintegration problems among OEF/OIF veterans in New York State (Schell \& Taneilian, 2011), no published studies have examined the challenges that veterans face when they return to college classrooms. Some universities have dedicated spaces for returning war veterans, but others have no special programs to assist them with reintegration into university life. Jill, a college student, discussed the challenges of returning from Iraq to a college campus filled with fellow student who did not understand her deployment experiences:

I really didn't talk to people about serving in Iraq when I got back because not really many people wanted to know stories. My friends didn't really understand. Like I don't talk to a lot of them anymore only for the fact that when I went away in their minds it was almost like 'well, she's not talking to me anymore so I'm not going to talk to her'. So we lost communications while I was over there and I took it as 'well, if you don't want to talk to me while I'm getting shot at and in a combat zone, then I don't want to be your friend'.

\section{Coping strategies}

Participants described post-deployment behaviors, thoughts, and perceptions that fit into three major coping strategies: behavioral avoidance, cognitive avoidance and behavioral approach. Each of those coping strategies is described in detail below. 


\section{Behavioral avoidance coping}

Consistent with prior research on coping mechanisms, women veterans engaged in various forms of behavioral avoidance coping strategies (Moos \& Schaefer, 1993). By using this approach, women engaged in behaviors aimed at replacing stressful deployment feelings with alternate sources of satisfaction. Women identified four major behavioral coping strategies they used to cope with post-deployment stress: binging and purging, compulsive spending, over-exercising, and prescription drug abuse. Consistent with prior studies, women veterans tended to overeat or binge eat as a coping mechanism (Arnow, Kenardy, \& Agras, 1995; Henderson \& Huon, 2002; Ozier et al., 2007; Timmerman \& Acton, 2001; de Zwaan, Nutzinger, \& Schoenbeck, 1994). Women veterans often described coupling their overeating with isolation. For example, Maria noted that she had spent nearly two months in an inpatient psychiatric unit shortly after her return from Iraq for PTSD and suicidal ideation. Her hospitalization helped "some", but she explained that she remains in a deep depression and has been unable to keep a job in the years since she returned from Iraq. To cope with her memories of Iraq, Maria relies on food.

When I get into my depression I will just go and buy food, even though I don't really have enough money to buy food. When the depression hits I just go to the grocery store and I go when there's no crowds, because I don't like crowds. But I buy whatever I want and then I sit on the couch, whether it be with chocolate or something else, and I buy enough to last me a week.

Similar to Maria, Grace relied on food control, as well as binging and purging, to help her cope with the sexual harassment she experienced during her deployment. As Ozier and colleagues recently noted, individuals who are experiencing extreme stress, such as Maria and Grace, can use food control and overeating as a maladaptive way of coping with their stress (Ozier et al., 2007).

Since I've returned from Iraq, I started to control my food and my intake of food and its gotten to the point where I mean literally I will only eat, I will only eat the same thing every day because I know exactly what I'm putting in my body and how much is going in and if I eat more than that there are times when I am so hungry that I'm like I need to eat something and I'll eat more and I'll go vomit because I know I can't have more than that. I know what I'm supposed to eat and then on days when I just can't take it anymore because I'm so hungry, I'll vomit 3 or 4 times just to make sure it's all out and laxatives and all that stuff. And every single day I measure my food. I know exactly what I'm putting in. I know exactly what I'm eating. I know what.....how much and all the different amounts and everything versus how much I work out and I can.....I know and if I don't...... if I'm feeling too bad and I can't do something during a certain day, I won't eat because I know that I'm not exercising to work that off. So it's like food is a hard struggle for me.

Other women used extreme degrees of exercise to cope with their stress. Studies on the relationship between physical activity and stress have been inconsistent, with some studies showing individuals exercise less when experiencing stress (Heslop et al., 2001; Ng \& Jeffery, 2003), while others showing an increase of exercise with stress (Spillman, 1990). Sarah, age 23, described her use of extreme exercise to cope with stress:

You know they always taught us to exercise. So when I returned, I would exercise to excess and really to excess to the point where I would be sick. But it would make me feel better about being home. It was very strange not to be able to control my emotions. It was like these very high highs and these very strange lows.
Exercise was my addiction and I was constantly throwing up. I got super skinny.

Other women in the study spoke of their inability to stop spending money once they returned from deployment. Women attributed this overspending to the stresses of returning to civilian life, and noted that most of the overspending occurred in the first year after return from deployment. Karen described what did to cope with the memories she was having of her military deployment:

My thing is I like to go to the casino by myself and I can be there for eight hours by myself and I don't hear anyone, I'm anonymous, no one knows who I am. I am just another person playing a slot machine. I can go shopping. It makes me feel good. I'm going to buy some cosmetics because it makes me feel good. I'm gonna order that pair of shoes because it makes me feel good. It's more impulsive now than it was (before Iraq).

Unlike their male veteran counterparts who may rely on atrisk alcohol use to help them cope with post-deployment stress (Erbes et al., 2007; Sayers, Farrow, Ross, \& Oslin, 2009), women in the study did not endorse alcohol, smoking, or illicit drug use as mechanisms to cope with stress. However, some women spoke of their increasing dependence on prescription drugs to help them manage their feelings. Grace, in particular, spoke of her reliance on her prescription medication for anxiety to help her manage the feelings she was having after her return from Iraq.

I think I definitely can overdo it with my medication and I find myself looking forward to the time when I can take my medicine at night because it just puts me in that, just that almost, you know, vegetative state where I'm just like, you know, almost drooling on myself and it just feels so good to just....it's almost like being drunk really.

\section{Cognitive avoidance coping}

One characteristic of women veterans that was similar across all types of avoidance behaviors was that women preferred to engage in many activities (substance abuse, overeating, shopping) in isolation. As Maria noted:

Yeah, I put on about twenty pounds when I came back. But I think mostly it's cause I would isolate myself. You know, I found myself, saying...ok, I don't want to be around people. I don't want to hear the stupid stuff they're talking about, you know?

Isolation has been identified by other researchers as a common coping strategy after return from deployment (California Department of Alcohol and Drug Programs, 2009; Goodman, Smyth, Borges, \& Singer, 2009; Vellenga \& Christenson, 1995). Rather than trying to reconnect with friends or family members or share their experiences with other veterans, women in the current study instead chose to remove themselves from others. Some women, such as Jean, reported that once they returned to the United States, the only way to cope with the feelings they experienced around their military service was to isolate themselves from their friends and family:

Where before I would've been devastated if me and him weren't close. I mean, we aren't talking now and I isolate myself in the bedroom, I read my books, I could care less. He wants me to sleep in the other room 'cause I snore so much since I have come back. Before that would've devastated me, now I don't care because I just want to be alone. 
Other researchers have noted that social support is a recognized resource for coping with stress and the isolation that may arise from poor coping mechanisms (Thoits, 1986). Social support can be defined as the availability of instrumental and emotional assistance through interpersonal relationships (Kocot \& Goodman, 2003). Social support can be provided by informal networks, including family, neighbors, and friends, or through formal networks, including community agencies and systems. Women in the current study rarely mentioned friends or family members as social support mechanisms, and only one woman mentioned relying on the statewide Vet Center as a social support network.

\section{Behavioral approach coping strategies}

While many women veterans spoke of the great difficulties they had readjusting to civilian life in the United States, several women spoke of the coping strategies they used to successfully navigate their post-deployment stress. By utilizing behavioral approach coping strategies (Moos \& Schaefer, 1993), some women were able to cope with stressful deployment experiences by taking concrete action to deal with the stressful experiences they had during deployment. Some women, like Jean, used exercise as a positive strategy, relying on regular routines, such as running and yoga, to help overcome negative emotions.

I purposely stretch. I have a yoga mat in the car. I find myself, go out to the park, find a quiet spot, and stretch. If I do nothing else for myself over the course of the day, that little bit of love is for me, and only me.

Unlike some of the women who sought isolation upon return from deployment, several women spoke of the importance of reaching out to others to help them through difficult postdeployment experiences. In particular, several women spoke of the importance of VA 'vet centers' that provided counseling and resources to veterans who had recently returned from combat. Carolyn, who had served as a medic in Iraq, was able to successfully cope with some of her negative feelings by relying on strategies her therapist had given her to manage her negative feelings:

My therapist at the Vet Center told me how to use breathing to cope with stress. When you can't sleep well, she taught me to put one hand on your chest, one hand on your belly and you breathe deeply and sense yourself on just the way your hand is going up and down when you're breathing. It puts me to sleep every time. I don't even need Tylenol PM anymore.

Several women spoke of the importance of coming together with other women veterans to share their experiences with deployment and support each other through difficult reintegration experiences. Women viewed the opportunity to speak with other women veterans as a therapeutic experience that allowed them to cope with some of the stressful experiences they were having. Carolyn shared:

You know, we women are all different; we all react differently, we all have different coping mechanisms, and we all have different ways of getting help. I like hearing what other women veterans say and laughing when I think, "Oh my God! I went through the same thing!. I can relate to what other women saw there.

Unfortunately, women could think of few opportunities that they had had to sit down with other women veterans and share their experiences. Though a few women spoke of the individual therapy they had received through the VA or through the vet centers, women were hard-pressed to think of support groups just for women veterans who wanted to receive support regarding their wartime experiences. Other women, such as Erica, noted that even if they wanted to connect with other women veterans through therapeutic support groups at the VA, they would not feel comfortable seeking VA services for their problems:

The VA is a place where men-wounded men or retired men go. But I feel that if I'm a woman veteran, or even if I'm a wounded woman veteran, I don't deserve to go to the VA because there still may be World War II, Korean, or Vietnam vets who need the VA. So I'm not going to go to the VA because there are so many other guys who need it more than I do.

\section{Discussion}

Women veterans in the study were no strangers to the stresses associated with war. Whether experiencing trauma associated with caring for critically injured victims of war, enduring sexual harassment or rape from fellow military personnel, or returning to parenting or marital relationships strained by the length of deployment, many women who served in OEF/OIF experienced substantial stress both during the war and upon return to the United States.

Women veterans used both used both behavioral approach and avoidance coping strategies as well as cognitive avoidance strategies for dealing with stress. As has been reported in other studies (California Department of Alcohol and Drug Programs, 2009; Goodman et al., 2009; Schell \& Taneilian, 2011), women veterans had a tendency to isolate themselves from others upon return from deployment. Rather than reaching out to family and friends to seek social support, some women relied on behavioral avoidance coping strategies, including overindulgence in food, prescription drugs, and exercise to alleviate the negative feelings they were having. However, other women mentioned behavioral approach coping strategies, including exercise, listening to music, breathing exercises, and speaking with other women veterans.

An important theme echoed across many of the interviews was the sense that women's experiences in war were not widely understood or recognized upon return to the United States. As noted in other studies (Mulhall, 2009), because women's roles and experiences in the military are often minimized or misunderstood by family, friends, and healthcare professionals, women themselves tend to minimize their contributions. Several women in the study indicated that they did not feel their physical and mental health ailments were worthy of VA care. In some cases women who needed treatment for their war-related health problems chose not to utilize their VA healthcare benefits, and either received no treatment for their problems or sought private care for their problems.

For some women veterans the transition back to the United States has been easy, but for many others it has been complicated by marital problems, loss of friendships, divorce, job loss, and trouble returning to pre-deployment daily routines. For those women with children, being absent from their child's life for up to two years caused significant disruption in the child's life, and resulted in a readjustment process for both mother and child upon return from deployment. None of the women in the study reported that they received any help with this family readjustment process from either the military or from the VA, and were left to renegotiate their relationships with their children on their own. Providing care to women and their families after return from deployment remains an important challenge, as the VA is not currently mandated to provide such services (American Legion, 2009).

It is unclear why women in the study did not seem to feel as though they deserved services provided by the VA, or why they did 
not advocate more strongly to receive the services they needed and deserved. Other researchers have suggested that, like Vietnam veterans, OEF/OIF veterans may have an ongoing sense of shame which may hamper efforts at self-advocacy, which may arise from perceptions regarding negative American attitudes toward war (Vellenga \& Christenson, 1995). Conversely, women veterans who may have experienced some form of military sexual trauma may be unwilling to utilize VA services, for fear of encountering the same types of individuals who may have perpetrated the sexual trauma. Finally, many women veterans who are returning to the United States after months of deployment may feel that, despite their own personal medical or mental health needs, the focus needs to shift away from their own personal needs to the needs of their children and other family members.

Importantly, several women in the study noted the importance of connecting with other women veterans to share their experiences. As echoed in other studies (Schell \& Taneilian, 2011), women expressed a need to get together in person with other women veterans, similar to Veterans of Foreign Wars (VFW) or veterans service organizations (VSOs) of previous war eras. Because some women choose not to use the VA for their healthcare needs, it is important that women are able to make these connections in their local communities or through state Departments of Veteran's Affairs. For example, the Connecticut Department of Veteran's Affairs sponsors the Connecticut Women Veterans' Network (CT VETNET), which was established to assist Connecticut women's veterans with information and access to benefits specifically for women veterans. Through this network, women can gain access to local resources and support networks for women veterans living in nearby communities.

There are several important policy implications from the current study. First, because some of the stressors that women have experienced during military service are related to military sexual trauma, women veterans need to have access to gender-specific mental health and substance abuse counseling. Currently, the VA offers nearly 100 substance abuse programs with specialized services targeted at women veterans. However, because not all women veterans seek VA care for these problems and conditions, the VA should establish collaborative relationships with state and community-level mental health and substance abuse agencies to provide access to needed care. In addition, because women veterans remain the primary caregivers of young children, childcare is a barrier for treatment for many women veterans seeking mental health and substance abuse treatment. The recent passage of PL-111163, the "Caregivers and Veterans Omnibus Health Services Act of 2010 " will allow the VA to carry out a 2-year pilot program to assess the feasibility of childcare for qualified veterans who are the primary caretakers of a child (Department of Veterans Affairs, 2010). Finally, the recent passage of the GI bill allows veterans to receive tuition subsidies for their college educations, but the Department of Veteran's Affairs must also work with college campuses to ensure they have the resources they need to support veterans. Given returning veterans are often juggling young families, jobs, injuries, and possibly mental health conditions sustained during OEF/OIF deployment, services need to be carefully tailored to these veterans' needs (Yonkman \& Bridgeland, 2009).

This study has several limitations. First, all women in the study had enrolled in the VA for healthcare, so these women may have been more likely to have been coping with difficult wartime experiences and may have been struggling with coping mechanisms to help with these experiences. Second, there was wide variation in the duration of time women in the study had returned from deployment. Some women had been back for three months, while others had returned from deployment over five years prior to this study. As a result, women were at various stages of their coping processes, and women who returned several years ago from deployment may have not remembered some of the coping mechanisms they used shortly after return from deployment. Third, all interviews were conducted in Connecticut and a large majority of the women were National Guard or Reserves members, so these interviews are not representative of the larger population of women veterans, particularly those women in active duty. Finally, the interviewers were blinded to the identities and mental health status of the women veterans interviewed for this study prior to the interview, and information regarding mental health status was not assigned to the research transcripts at the conclusion of the interview. Consequently, we were not able to differentiate coping strategies based on mental health status of the women veterans in this study.

In conclusion, our research helps to elucidate the experiences of women veterans who have served in Iraq and Afghanistan, and outline some of the major coping strategies these women are using to help them negotiate the stresses of military service. Distinctions between negative and positive coping strategies are important because it is likely that the positive coping strategies may yield better long-term outcomes and may be best promoted by postdeployment interventions specific to women veterans. Interventions to assist women veterans in the coping process must occur at multiple levels (individual, family, community), and from multiple institutions (VA, community-based providers). Appropriate interventions should increase the likelihood of healthy recovery from war-related stress, and secondary and tertiary prevention strategies are important components in post-deployment healthcare for women veterans.

\section{Acknowledgments}

The authors are very grateful to Tan P. Pham, MPH, and Blair Harrison, MPH, for their contributions to this manuscript.

\section{References}

Adler-Baeder, F., Pittman, J. F., \& Taylor, L. (2006). The prevalence of marital transitions in military families. Journal of Divorce E Remarriage, 44(1), 91-106.

American Legion. (2009). Women veterans: Identifying risks, services and prevention. Arnow, B., Kenardy, J., \& Agras, W. S. (1995). The emotional eating scale: the development of a measure to assess coping with negative affect by eating. International Journal of Eating Disorders, 18(1), 79-90.

Baker, D. G., Heppner, P., Afari, N., Nunnink, S., Kilmer, M., Simmons, A., et al. (2009) Trauma exposure, branch of service, and physical injury in relation to mental health among U.S. veterans returning from Iraq and Afghanistan. Military Medicine, 174(8), 773-778.

Bianchi, S. M., Milkie, M. A., Sayer, L. C., et al. (2000). Is anyone doing the housework? trends in the gender division of household labor. Social Forces, 79, 191.

Bruner, V. E., \& Woll, P. (2011). The battle within: understanding the physiology of war-zone stress exposure. Social Work in Health Care, 50(1), 19-33.

California Department of Alcohol and Drug Programs. (2009). Veterans resources: Posttraumatic stress disorder.

Carter-Visscher, R., Polusny, M., Murdoch, M., Thuras, P., Erbes, C., \& Kehle, S. (2010). Pre-deployment gender differences in stressors and mental health among U.S National Guard troops poised for Operation Iraqi Freedom deployment. Journal of Traumatic Stress, 23(1), 78-85.

Cohen, B., Gima, K., Bertenthal, D., Kim, S., Marmar, C., \& Seal, K. (2010). Mental health diagnoses and utilization of VA non-mental health medical services among returning Iraq and Afghanistan veterans. Journal of General Internal Medicine, 25(1), 18-24.

Department of Defense. (2006). Marital and child status of active duty women Defense Manpower Data Center.

Department of Defense. (2010). Deployed demographics of single servicemembers. Defense Manpower Data Center.

Department of Veterans Affairs. (2010). Advisory committee on women veterans report, 2010. Women veterans-A proud tradition of service. http://www.va.gov/ WOMENVET/docs/ACWV_Report_2010.pdf Accessed 26.07.11.

Donegan, C. (1996). New military culture: do women, blacks, and homosexuals get fair treatment? CQ Researcher, 6, 361-384.

Dutra, L., Grubbs, K., Greene, C., Trego, L., McCartin, T., Kloezeman, K., et al. (2011). Women at war: implications for mental health. Journal of Trauma and Dissociation, 12, 25-37. 
Erbes, C., Westermeyer, J., Engdahl, B., \& Johnsen, E. (2007). Post-traumatic stress disorder and service utilization in a sample of service members from Iraq and Afghanistan. Military Medicine, 172(4), 359-363.

Engel, C. C., Liu, X., McCarthy, B. D., Miller, R. F., \& Ursano, R. J. (2004). Relationship of physical symptoms to post-traumatic stress disorder among veterans seeking care for Gulf war-related health concerns. Psychosomatic Medicine, 62, 739-745.

Farley, K. M. J., \& Catano, V. M. (2006). The battlefield as workplace: violence in warfighting, pp. 281-308. In E. K. Kelloway, J. Barling, \& J. Hurrell (Eds.), Handbook of workplace violence. Thousand Oaks, CA: Sage.

Ferrier-Auerbach, A., Erbes, C., Polusny, M., Rath, M., \& Sponheim, M. (2010). Predictors of emotional distress reported by soldiers in a combat zone. Journal of Psychiatric Research, 44(7), 470-476.

Foster, E. M. (2011). Deployment and the citizen soldier. Medical Care, 49, 301-312.

Goodman, L. A., Smyth, K. F., Borges, A. M., \& Singer, R. (2009). When crises collide: how interpersonal violence and poverty intersect to shape women's mental health and coping. Trauma, Violence, \& Abuse, 10(4), 306-329.

Hoge, C. W., Castro, C. A., Messer, S. C., McGurk, D., Cotting, D. L., \& Koffman, R. L. (2004). Combat durty in Iraq and Afghanistan, mental health problems, and barriers to care. New England Journal of Medicine, 351, 13-22.

Hoge, C. W., Terhakopian, A., Castro, C. A., Messer, S. C., \& Engel, C. C. (2007) Association of posttraumatic stress disorder with somatic symptoms, health care visits, and absenteeism among Iraq war veterans. American Journal of Psychiatry, 164, 150-153.

Henderson, N. J., \& Huon, G. F. (2002). Negative affect and binge eating in overweight women. British Journal of Health Psychology, 7(1), 77.

Heslop, P., Smith, G. D., Carroll, D., Macleod, J., Hyland, F., \& Hart, C. (2001) Perceived stress and coronary heart disease risk factors: the contribution of socio-economic position. British Journal of Health Psychology, 6(2), 167.

Jakupcak, M., Cook, J., Imel, Z., Fontana, A., Rosenheck, R., \& McFall, M. (2009) Posttraumatic stress disorder as a risk factor for suicidal ideation in Iraq and Afghanistan war veterans. Journal of Traumatic Stress, 22(4), 303-306.

Joint Improvised Explosive Device Defeat Organization Annual Report, FY09. (2009) Accessed online 3/3/11: https://www.jieddo.dod.mil/content/docs/20090909 FULL_2009\%20Annual\%20Report_Unclassified_v1_lr.pdf.

Kang, H. K. (2006). VA health care utilization among OIF/OEF veterans. http://www. academyhealth.org/2008/monday/tmarshalls/6_9_2008_11_30/deyton1.ppt Retrieved from.

Kelley, M. L., Hock, E., Jarvis, M. S., Smith, K. M., Gaffney, M. A., \& Bonney, J. F. (2002). Psychological adjustment of navy mothers experiencing deployment. Military Psychology, 14(3), 199-216.

Kimerling, R., Gima, K., Smith, M. W., Street, A., \& Frayne, S. (2007). The veterans health administration and military sexual trauma. American Journal of Public Health, 97(12), 2160-2166.

Kimerling, R., Street, A., Pavao, J., Smith, M. W., Cronkite, R. C., Holmes, T. H., et al. (2010). Military-related sexual trauma among veterans health administration patients returning from Iraq and Afghanistan. American Journal of Public Health, 100(8), 1409-1412.

King, L. A., King, D. W., Fairbank, J. A., Keane, T. M., \& Adams, G. A. (1998). Resiliencerecovery factors in post-traumatic stress disorder among female and male Vietnam veterans: hardiness, postwar social support, and additional stressful life events. Journal of Personality and Social Psychology, 74, 420-434.

King, L. A., King, D. W., Vogt, D. S., Knight, J. A., \& Samper, R. E. (2006). Deployment risk and resilience inventory: a collection of measures for studying deployment-related experiences of military personnel and veterans. Military Psychology, 18, 89-120.

Kocot, T., \& Goodman, L. A. (2003). The roles of coping and social support in battered women's mental health. Violence Against Women, 9, 1-24.

Lambert, L. (2004). Reclaiming child soldiers' lost lives. Journal of the American Medical Association, 292, 553-554.

Lazarus, R., \& Folkman, S. (1984). Stress, appraisal, and coping. New York: Springer.

Linos, N. (2009). Rethinking gender-based violence during war: is violence against civilian men a problem worth addressing? Social Science \& Medicine, 68(8), 1548-1551.

McDevitt-Murphy, M. E., Williams, J. L., Bracken, K. L., Fields, J. A., Monahan, C. J., \& Murphy, J. G. (2010). PTSD symptoms, hazardous drinking, and health functioning among U.S.OEF and OIF veterans presenting to primary care. Journal of Traumatic Stress, 23(1), 108-111.

Milliken, C. S., Auchterlonie, J. L., \& Hoge, C. W. (2007). Longitudinal assessment of mental health problems among active and reserve component soldiers returning from Iraq war. Journal of the American Medical Association, 298, 2141-2148.

Moos, R. H., \& Schaefer, J. A. (1993). Coping resources and processes: current concepts and measures. In L. Goldberger, \& S. Breznitz (Eds.), Handbook of stress: Theoretical and clinical aspects. New York: The Free Press.

Mulhall, E. (2009). Women warriors supporting she 'who has borne the battle'. Iraq and Afghanistan Veterans of America,

$\mathrm{Ng}$, D., \& Jeffery, R. (2003). Relationships between perceived stress and health behaviors in a sample of working adults. Health Psychology, 22, 638-642.

Ozier, A. D., Kendrick, O. W., Knol, L. L., Leeper, J. D., Perko, M., \& Burnham, J. (2007). The eating and appraisal due to emotions and stress (EADES) questionnaire: development and validation. Journal of the American Dietetic Association, 107(4), 619-628.

Rodrigues, C., \& Renshaw, K. (2010). Associations of coping processes with posttraumatic stress disorder symptoms in national guard/reserve service members deployed during the OEF/OIF era. Journal of Anxiety Disorders, 24, 694-699.

Sayers, S., Farrow, V., Ross, J., \& Oslin, D. (2009). Family problems among recently returned military veterans referred for a mental health evaluation. Journal of Clinical Psychiatry, 70(2), 163-170.

Sharkansky, E. J., King, D. W., King, L. A., Wolfe, J., Erickson, D. J., \& Stokes, L. R. (2000). Coping with Gulf War combat stress: mediating and moderating effects. Journal of Abnormal Psychology, 109, 188-197.

Schell, T., \& Taneilian, T. (2011). A needs assessment of New York state veterans: Final report to the New York state health foundation. Santa Monica: RAND Corporation.

Schnurr, P. P., Lunney, C. A., Bovin, M. J., \& Marx, B. P. (2009). Posttraumatic stress disorder and quality of life: extension of findings to veterans of the wars in Iraq and Afghanistan. Clinical Psychology Review, 29(8), 727-735.

Seal, K. H., Maguen, S., Cohen, B., Gima, K. S., Metzler, T. J., Ren, L., et al. (2010). VA mental health services utilization in Iraq and Afghanistan veterans in the first year of receiving new mental health diagnoses. Journal of Traumatic Stress, 23(1), 5-16.

Seal, K. H., Metzler, T. J., Gima, K. S., Bertenthal, D., Maguen, S., \& Marmar, C. R. (2009). Trends and risk factors for mental health diagnoses among Iraq and Afghanistan veterans using department of veterans affairs health care, 2002-2008. American Journal of Public Health, 99(9), 1651-1658.

Spillman, D. (1990). Survey of food and vitamin intake responses reported by university students experiencing stress. Psychological Reports, 66, 499-502.

Street, A. E., Vogt, D., \& Dutra, L. (2009). A new generation of women veterans: stressors faced by women deployed to Iraq and Afghanistan. Clinical Psychology Review, 29(8), 685-694.

Suvak, M. K, Vogt, D. S., Savarese, V. W., King, D. W. \& King, L. A. (2002). Relationship of war-zone coping strategies to long-term general life adjustment among Vietnam veteran: combat exposure as a moderator variable. Personality and Social Psychology Bulletin, 28, 974-985.

Thoits, P. A. (1986). Social support as a coping assistance. Journal of Consulting and Clinical Psychology, 54, 416-423.

Timmerman, G. M., \& Acton, G. J. (2001). The relationship between basic need satisfaction and emotional eating. Issues in Mental Health Nursing 22(7), 691-701.

United Nations. (1993). General Assembly: 48/104: Declaration on the elimination of violence against women. Accessed 29.07.11. www.un.org/documents/ga/res/48/ a48r104.htm.

Vellenga, B., \& Christenson, J. (1995). Healing the wounds of war: the Vietnam veteran after operation desert storm. Perspectives in Psychiatric Care, 31(4), 5-8. Vogt, D., Pless, A., King, L., \& King, D. (2005). Deployment stressors, gender, and mental health among military personnel. Journal of Traumatic Stress, 20, 27-38.

Vogt, D., Samper, R., King, D., King, L., \& Martin, J. (2008). Deployment stressors and posttraumatic stress symptomology: comparing active duty and national guard/ reserve personnel from Gulf War I. Journal of Traumatic Stress, 21, 66-74.

Vogt, D. S., \& Tanner, I. R. (2007). Risk and resilience factors for posttraumatic stress symptomotology in Gulf War I veterans. Journal of Traumatic Stress, 20, 27-38.

Yaeger, D., Himmelfarb, N., Cammack, A., \& Mintz, J. (2006). DSM-IV diagnosed posttraumatic stress disorder in women veterans with and without military sexual trauma. Journal of General Internal Medicine, 21(S3), S65-S69.

Yonkman, M. M., \& Bridgeland, J. M. (November 11, 2009). All volunteer force: From military to civilian service. Civic Enterprises. www.civicenterprises.net/pdfs/ allvolunteerforce.pdf Accessed 29.07.11.

de Zwaan, M., Mitchell, J., Seim, H., Specker, S., Pyle, R., Raymond, N., et al. (1994). Eating related and general psychopathology in obese females with binge eating disorder. International Journal of Eating Disorders, 15, 43-52. 